\title{
Lexical Patterns and Cohesiveness of Selected Poems: Bases for Deriving Themes
}

\author{
Jahnese D. Asuncion and Marlina L. Lino
}

\begin{abstract}
Lexical patterning has been considered as a new, interesting, and academic manner of discussing poetry. Themes embedded in poems can be particularly derived easier through a close look at the lexical patterns and cohesiveness of a text. This study, therefore, was conducted to describe the lexical patterns and cohesiveness of selected poems and use these as bases for determining their respective themes.

The descriptive research design particularly content analysis was utilized to identify the lexical patterns in the selected poems. The lexical patterns were categorized based on the extensive composition written by Transkanen. Moreover, the cohesiveness of each of the poems was determined through a formula adapted from Goodarzi. The identified lexical patterns and cohesiveness in each of the poems were used to derive the theme. The lexical patterns, cohesiveness and derived themes were validated by experienced literature teachers.

Results reveal that the poems are rich in lexical patterns and majority of them are cohesive. Hence, the derivation of theme is easier and faster.
\end{abstract}

Index Terms-Cohesiveness, lexical patterns, poems, literatures of the world, themes.

\section{INTRODUCTION}

Poetry is a very special genre in literature specifically because of the poetic language inherent in it. Poems are generally shorter in length than narratives and essays, but most likely, they tell more than the number of words used [1]. The meaning of poems comes from uncovering and expanding the key words in them. Understanding poems lies on how wide the students' knowledge of the words is and on how skillful they are in unlocking the meaning of these key words mainly through context clues and close reading technique.

In teaching poetry then, unlocking vocabulary difficulties, identifying the denotations and connotations, emphasizing word patterns or relations, uncovering the underlying meanings of symbols and other figures of speech, are undeniably very important [2]. Words must be studied and taught carefully in the context of the lines in which they appear. The poetic text is completely detached from the external world; thus, it creates a context of situation for itself through special patterning of language [3]. Many words have more than one meaning, and poets are unusually sensitive to the multiple meanings and shades of meaning in words [4].

Manuscript received June 15, 2017; revised September 10, 2017.

J. D. Asuncion is with the Mariano Marcos State University College of Teacher Education (MMSU CTE), Laoag City, 2900, Philippines (e-mail: nesedomingo@gmail.com).

M. L. Lino is with the Mariano Marcos State University College of Arts and Sciences (MMSU CAS), City of Batac, 2906, Philippines (e-mail: mlino_mmsu@yahoo.com).
Hence, the words in the poem command attention.

However, it is also because of this characteristic and quality of words that students usually find it difficult to read,

Understand, and analyze poetry. They feel that some poems employ unfamiliar language to convey obscure 'meanings'.

Usually, in the first reading of any poem, students feel that it does not make any sense. However, since they are compelled to read poems as it is a requirement in their literature or reading classes, they try to reread a poem as many times until certain lines will captivate their imaginations and seem to encourage them to read more.

The most difficult part of poetry analysis is the derivation of theme because it is a controlling thought or idea the writer presents to the reader that may be deep, difficult to understand, or even philosophical [5]. This idea is crafted and developed throughout the poem and can be identified by assessing the poem's rhythm, setting, tone, mood, diction and title. It is rarely stated explicitly.

Locating and identifying the theme is crucial to understanding dominant ideas [6]. Generally, a theme has to be extracted as the reader explores the words and passages of a work.

To be able to successfully deduce and comprehend the theme of a poem, the students need to methodically examine and make careful observations on the separate aspects of the text. One of the various ways to do this is through lexical patterning. Analyzing the lexis and lexical patterns in the poem adds to the aesthetic enjoyment and deep realization of the holistic meaning of the poem [7].

Lexical patterning is a part of lexical semantics which examines the relationships among word meanings. It is an investigation of how the lexicon is organized and how the meanings of lexical items are interrelated. This type of investigation first appeared in the studies of Hasan [8], who applied a discourse approach to literature and considered the literary effect to be the result of language patterns.

The lexical patterns or semantic fields evident in a poem, were identified by Transkanen [9] as antonymy, collocation, hyponymy, meronymy, repetition and synonymy. Moreover, Halliday and Hasan [10] popularized lexical cohesion which is equivalent to lexical pattern in a text. Lexical cohesion can be found between content words or lexical items which may be in the aforementioned six sense relations.

Antonymy is a type of sense relationship between or among lexical items that have opposite meanings. Collocation is one of the types of lexical patterns that refer to two or more lexical items that naturally co-occur or combine frequently in the English language. Example of collocation are lion's roar, fast food and excruciating pain. Meanwhile, hyponymy is a linguistic term that denotes to a specific word 
used to designate a member of a class, for instance, daisy and rose are hyponyms of flower. On the other hand, meronymy pertains to a part-whole relationship between lexical items, such as finger and hand. Repetition refers to the mere identical recurrence of a preceding lexical item. Lastly, synonymy pertains to the similarity of meaning and/or reference between or among lexical items.

There are studies already conducted and published using lexical patterns as tools in analyzing poems, literary styles and authorial styles. Two of these became the inspiration of this study -- one is by Goodarzi [7] titled, Lexical Patterning in Poetic Text: Analyzing Literary Style, and the other by Ebi Yeibo [11] titled, Patterns of Lexical Choices and Stylistic Function in J.P. Clark-Bekedermo's Poetry.

However, there is none which ventured on using lexical patterns solely to derive the themes of selected poems particularly those used in the teaching of a General Education subject in the tertiary level, that is, Literatures of the World. Many of the said researches focused on the works of a single author or on a single work such as Saaed's [12] study, An Analysis of Lexical Meaning in Edwin Muir's 'The Combat,' and Ruxandra's [13] study, Lexical Peculiarities of D.H. Lawrence's Poetic Prose.

This study recognizes that lexical patterns play a considerably important role in contributing to maximal coherence of a poetic text, which eventually leads in the easy derivation of its theme. Every lexical item contributes to produce images in poetry, directly or indirectly [14]. Once an image has been established in a poem, all lexical items in the poem may be applied to it by extending their meaning metaphorically.

Moreover, lexical items which seem unrelated to the established images usually create more images for the purpose of making the experience gained from the poem more complex [15]. In this regard, strings of related lexis in a poem can help the reader to understand how the poem creates and co-ordinates different levels of imagery. These diverse levels of imagery convey the sense of an experience in a poem which can lead to realizing its universal message or theme. It can be pointed out that the poet uses words to suggest various contexts in which the reader is encouraged to be involved and experience the same emotional, intellectual and intuitional senses of the poet [16].

However, many readers usually enter the said experience rather confused as to what or which is meant by the poet [17]. Readers usually have an initial feeling that they know that all are meant, but also that none are exactly meant [2]. But, readers can resolve this problem by extending the writer's experience through comprehending the poet's many suggested contexts [4]. Readers, therefore, may enter the poet's visions by understanding and correlating the words and the contexts used in the poem. In the interplay of these different contexts, readers eventually are able to recreate the poet's experience [14].

With these, it can be strongly advocated that any single lexical item or a group of related items may produce a context in poetry. Each context created in this way gets the reader involved in a momentary experience with the poet's state. The nearly created context contrasts or combines with other contexts. In other words, this sort of shift of contexts creates an 'aesthetic view' of poetry [7]. This view sees poetry as an abstract experience of language in which rapid shifts of contexts, helped by the movement of sound and grammar, do not give the reader an impression, but a series of experiences [14].

These experiences deepen the appreciation of readers, leading them to derive the theme from a poem. Usually, the theme, the main idea or underlying meaning of a literary work which may be stated directly or indirectly can be summed in a single word (e.g. passion, heroism, friendship). The most common contemporary understanding of theme is that it is an idea or point that is central to a piece. However, the standard way is to express it in a complete simple statement because the theme is also considered as the specific and complete message of the literary piece which reflects universal truth.

Universal themes developed in a story, poem, or play ultimately expand the students' knowledge of being human by the expression of experiences through different perspectives. Therefore, deriving the theme seems to be the culmination of any analysis and appreciation endeavour on a literary piece because of the theme's characteristics of timeliness and universality. Just as a scientist examines a specimen to prove a hypothesis, the literary analyst has a thesis to prove. Like a scientist who methodically examines separate aspects of a specimen such as its appearance, movements, and responses to environmental factors, the literature student is expected to make careful observations of the individual part of a literary piece. This examination takes time and concentrated effort.

\section{OBJECTIVES OF THE STUDY}

This study aimed to identify and describe the lexical patterns used in selected poems considered in the teaching of a General education subject in the tertiary level, that is, Literatures of the World. It also aimed to determine the cohesiveness of these poems based on the identified lexical patterns. These were subsequently used as bases in deriving the theme of each of the poems.

\section{SIGNIFICANCE OF THE STUDY}

Results of this study could serve as guide for teachers of literature on how to do lexical patterning and how to identify the cohesiveness of poems which can be used as bases for deriving themes. These could likewise help them discuss poems in a more academic manner.

Second, this study proves that the more cohesive a poem is, the easier the theme could be derived. Results of this study, therefore, could aid teachers in choosing wisely poems to be discussed in class by considering the cohesiveness of the poetic texts so that deriving the theme becomes simpler.

Results of the study could likewise benefit students. With the lexical patterns identified and the themes already derived, students can better understand and appreciate the poems. Moreover, with the results, students can do independent study and analysis of the poems. They are also provided a guide in the process of identifying and describing lexical patterns as well as cohesiveness of poems thereby leading them to better understanding and appreciation which culminate with the deriving of themes. 
In addition, the lexical patterns can give richer opportunities for students to learn vocabulary not just in the sentence level but also in discourse and literary levels. The process of describing the lexical patterns can help students gain wider understanding and appreciation of the beauty of words in poetry.

Furthermore, the results could likewise encourage teachers and students to use lexical patterning to derive themes from other literary genres like essays and short stories.

Finally, the results could provide insights and inspiration among instructional materials developers for them to enrich students' experiences in learning poetry by considering lexical patterning and the cohesiveness of the texts that they consider for study.

\section{THEORETICAL AND CONCEPTUAL FRAMEWORK}

This research was anchored on the Theory of Lexical Coherence which was popularized by Halliday and Hasan [10] and emphasized by several stylisticians in different titles such as: cohesion of foregrounding [18]; consistency of foregrounding [8]; motivated foregrounding [3]; semantic drift [19]; independent coherence [17] and literary coherence [16]. In classifying the sources for lexical cohesiveness, the said theory forwards a system of categories which are collectively and widely called the lexical patterns or fields, although, the number and types of the categories vary from one author to another. However, since they all comprise the same notions (only subdivided differently), the categorization used in this research is taken from the extensive composition written by Transkanen [9] which mainly refers to Halliday and Hasan [10].

Halliday and Hasan [10] emphasized that cohesiveness is linguistically explicit and signals underlying semantic relationship between text elements. In contrast to grammatical cohesiveness, lexical cohesiveness is the cohesive effect achieved by the selection of vocabulary [3]. Thus, a speaker or writer's either conscious or unconscious selection of certain lexical items that are in some way connected to each other creates lexical cohesiveness. The connections of these select lexical items are identified through the principle governing lexical patterning.

Lexical cohesiveness, therefore, is the central device for making texts hang together experientially, defining the meaning or general message of a text. Typically, lexical cohesiveness makes the most substantive contribution to texture. According to Hasan [8], around 40-50 percent of a text's cohesive ties are lexical.

In its simplest manifestation, lexical cohesiveness operates with repetition, either through simple string repetition or repetition by means of inflectional and derivational variants of the word contracting a cohesive tie. The more complex types of lexical cohesiveness work on the basis of the semantic relationships between words in terms of sense relations, such as collocation, synonymy, hyponymy, antonymy and meronymy.

In the study of Transkanen [9], these sense relations are called the six primary paradigmatic types of lexical patterns. He elaborated that basically, words are attached to categories, groupings or patterns. Pattern refers to the regular arrangement or order which may be repetitive or prevalent.
Halliday [3] forwards that lexical patterns exhibit many properties and are dynamic, accommodating new empirical evidences based on denotations, connotations, imageries and analogies.

Fig. 1 shows the framework of the study.

The themes embedded in the poems, represented as the core of this study, can be derived easier and faster using the lexical patterns and lexical cohesiveness as bases. With the proper identification and appreciation of the theme, the students eventually can better understand and appreciate the piece and literature in general.

Contrary to the layman's impression that deriving themes is superficial and effortless, experienced literature teachers recognize that directing a group of students to draw, establish and agree on a specified theme from a literary piece requires much effort, concentration, creativity and patience. Deriving the theme is the most important aspect of literary study because it is in the identification and analysis of the theme where students gain knowledge and inspiration of becoming more humane. Themes are not accepted by sharing a quick presumption or conclusion based on the students' perceptions only. Since the theme is recognized as the universal message, it must be if not very similar, very close to what the poet intends his or her creation to convey.

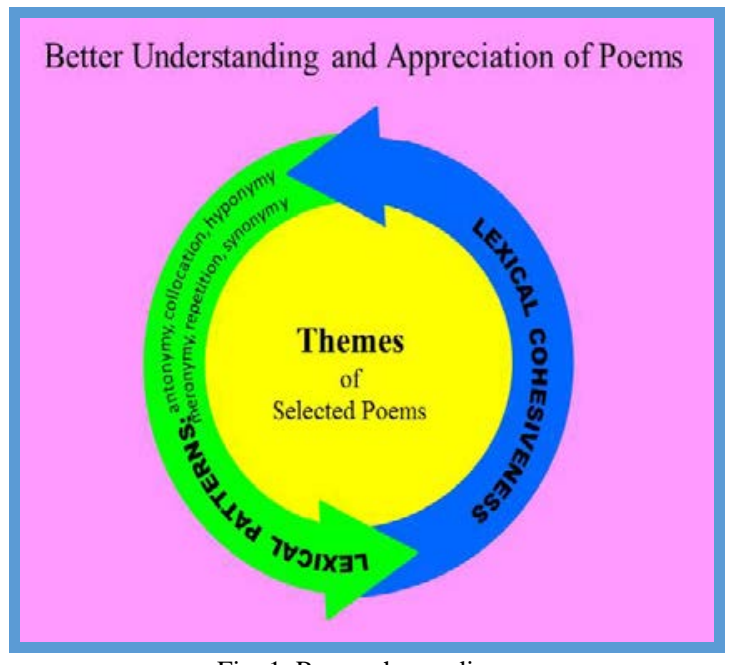

Fig. 1. Research paradigm

Poetic texts adopt special patterning of lexical entries in order to function properly. In poems, unrelated words are apparently unified by the poet through the interplay existing among different layers of words and meanings.

The connection among lexical items and lexical patterns activates semantic features which have a common point of reference. This point of reference in literary pieces is the theme. Thus, the value of each of these lexical items lies in their composite character which represents a reconciling of codes and context relations.

On one hand, lexical cohesiveness concerns the ways in which the components of the surface text (the actual words) are mutually connected within a sequence. The value of every lexical item can be determined with reference to its neighboring words. Hence, the more lexical associations (lexical patterns) there are in the poem, the more cohesive is the poem. The more lexical cohesive the poem is, the easier is the derivation of its theme.

The understanding and appreciation of the theme 
crystalizes any study or analysis of poems. Without this, the discussion of a poem is merely a summary of its components or structure. Better appreciation of the literary piece comes with the truthful investigation of the poem's theme.

\section{Methodology}

This study used the descriptive research design particularly content analysis. The method of content analysis is often used in descriptive research in which the subjects of empirical documentation such as written texts and artifacts are analyzed and given meaning [20]. It is considered a scholarly method in the humanities by which texts are studied as to authorship, authenticity and meaning [21].

In this study, the six-phased thematic analysis guide by Braun and Clarke [22] was adapted to specifically demonstrate associations and contextually infer from the chosen text-type (poems). The six phases include: becoming familiar with the data, generating initial codes, searching for themes, reviewing themes, defining and naming themes, and producing the report.

Fifteen poems from Literatures of the World were considered in the study. Literatures of the World is a General Education course in all curricular offerings in the tertiary level in the Philippines. A survey among instructors and professors of Literature in the universities and colleges in Ilocos Norte, Philippines was initially undertaken to determine which of the poems listed in the course syllabus, references and textbooks in World Literature are used by these instructors and professors in their classes. The top 15 poems identified were taken as specimen texts. Furthermore, the literature instructors and professors were interviewed to affirm if the said poems are the ones discussed in their classes. The said number of poems was considered sufficient for comprehensive analysis, lexical patterning and drawing of themes.

Table I shows the complete list of poems analyzed in this study including the authors and the countries which they represent.

TABLE I: LIST OF POEMS ANALYZED

\begin{tabular}{lll}
\hline Poems & Origin & Poet \\
\hline Africa & Africa & D. Diop \\
How Do I Love Thee & England & E.B.Browning \\
Invictus & England & W.E.Henley \\
The Little Rain & China & Tu Fu \\
On Friendship & Lebanon & K. Gibran \\
On Love & Lebanon & K. Gibran \\
Psalm 23 & Israel & King David \\
Psalm of Life & America & H.W. Longfellow \\
The Road Not Taken & America & R. Frost \\
The Rhodora & America & R.W. Emerson \\
Song to Celia & England & B. Jonson \\
Sonnet 1 & Philippines & J.G.Villa \\
Stopping by Woods & England & R.Frost \\
Telephone Conversation & Africa & W. Soyinka \\
Three with the Moon & China & Li Po \\
\hline
\end{tabular}

In the initial phase of analysis, the researchers closely read the poems and created an initial list or lexical map illustrating the sense relations of the words used in the poems. Each poem was read and reread as many times as needed for the researchers to grasp fully the relationship between or among the words used. The close reading technique often used in formalist, deconstructionist and semiotic literary criticism was done in each of the fifteen poems. In the lexical map, all the possible types of lexical patterns were determined from the poem. The tracing or mapping was illustrated through the use of color codes. Each type of lexical pattern was assigned a color code. However, in the final manuscript, only the three dominant types of lexical pattern were presented in the mapping because it is found out that these three major types of lexical patterns foremostly point to the theme.

After the mapping, the words that were identified as having common sense relations were classified and labeled.

The classification are as follows: antonymy, collocation, hyponymy, meronymy, repetition and synonymy. This grouping is very crucial because it is where the researchers collapsed data into labels in order to create the lexical patterns and establish the number of lexical patterns for more efficient derivation of themes. An explicit listing of lexical patterns was constructed for each of the poems. This was done for the purpose of clearly grouping the patterns, proper counting of the lexical items for the computation of the lexical cohesion and clear verification of the appropriateness of the groupings of the lexical items. An example of mapping done in all the poems is presented in the Results and Discussion (D).

The complete list of lexical patterns include the number of lexical patterns (LP), the lexical items belonging to each of the patterns (LI), the source or specific lines from the poem where the lexical items are found $(S)$ and the sense relation of the lexical items belonging to a certain pattern (SR). Refer to Appendix D for the samples of complete listings of lexical patterns.

Using the formula adapted from Goodarzi [7] as presented below, the researchers determined the degree of cohesiveness of the poems.

$$
\begin{aligned}
& \bar{x} L e x D e C F=\frac{\sum L \text { exDeCFs(in one poem) }}{\text { LexCoFD }} \\
& =\text { Degree/Percentage of Lexical Cohesiveness of a poem } \\
& =\text { Degree/Percentage of Ease of Thematization } \\
& \text { Where: } \\
& \text { LexDeCF }=\frac{\text { Lexical Items belonging to each Cohesion Field }}{\text { Total number of words }} \times 100 \\
& \text { LexCoFD }=\text { Total number of Lexical Cohesion Field present in a poem } \\
& \text { Lexical Cohesion Field = Lexical Cohesion Type by Halliday and Hasan } \\
& \text { (1974)Antonymy, Collocation, Hyponymy, } \\
& \text { Metonymy, Repetition, Synonymy }
\end{aligned}
$$

The results were given descriptive interpretations through the weighted mean scale presented in the next page. The computations determined the ease of eliciting the theme of the poem and the number of themes that can be elicited from the poem.

After the computations, the researchers re-examined the words grouped into each lexical pattern and synthesized their suggested holistic meaning (sense relation). The interrelationships of the lexical patterns were analyzed. The researchers related one lexical pattern to another or to others to determine if these lexical patterns are signifying the same notion. In order to do this, the researchers referred back to the poem several times as possible and consulted the dictionary so that both the connotative and denotative meanings of the words were considered in deriving the themes. Apparent 
literary devices such as figures of speech, tone and mood were also considered and related to the notions signified by the lexical patterns to make sure that the interpretations and analyses were accurate and substantial.

The identified lexical patterns and derived themes were first reviewed by the members of the advisory committee. Their comments and suggestions were considered in improving the mapping, listing and drawing of themes. After which, the researchers sought the help of three other professors who are experienced teachers of literature who served as validators. They closely went over the identified lexical patterns, lexical cohesiveness and derived themes of the selected poems and determined their appropriateness and acceptability.

This phase of the research is very important because the accuracy of the patterns and sense relations of the words were checked. The accuracy of the patterns determined the accuracy of the themes drawn from the said patterns. The suggestions and inputs of the validators were considered in the analysis and presentation of findings.

Moreover, this study used frequency count in identifying the number of lexical items belonging to each cohesion field. The mean of the Lexical Cohesion Field ( $\bar{x}$ LexDeCF) of each of the 15 poems analyzed were interpreted through the following weighted mean scale:

$\begin{array}{ll}\text { Weighted Mean } & \text { Descriptive Interpretation } \\ 1.00-1.80 & \text { Very Highly Cohesive } \\ 1.81-2.60 & \text { Highly Cohesive } \\ 2.61-3.40 & \text { Cohesive } \\ 3.41-4.20 & \text { Slightly Cohesive } \\ 4.21-5.00 & \text { Not Cohesive }\end{array}$

\section{RESULTS AND DISCUSSIONS}

This section presents the results and findings of the study. It presents tables illustrating the types of lexical patterns evident in selected poem and how cohesive the selected poems are.

TABLE II: SuMmary OF LeXICAL PATTERNS OF THE SELECTED POEMS

\begin{tabular}{|c|c|c|c|c|c|c|c|}
\hline \multirow{2}{*}{ Poems } & \multicolumn{6}{|c|}{ Types of Lexical Patterns } & \multirow{2}{*}{$\mathrm{N}$} \\
\hline & A & $\mathrm{H}$ & $\mathrm{C}$ & M & $\mathrm{R}$ & S & \\
\hline Africa & $\sqrt{ }$ & $\sqrt{ }$ & $\sqrt{ }$ & $\sqrt{ }$ & $\sqrt{ }$ & $\sqrt{ }$ & 6 \\
\hline How Do I Love Thee & $\sqrt{ }$ & $\sqrt{ }$ & $\sqrt{ }$ & $\sqrt{ }$ & $\sqrt{ }$ & $\sqrt{ }$ & 6 \\
\hline Invictus & & $\sqrt{ }$ & $\sqrt{ }$ & $\sqrt{ }$ & $\sqrt{ }$ & $\sqrt{ }$ & 5 \\
\hline The Little Rain & $\sqrt{ }$ & $\sqrt{ }$ & $\sqrt{ }$ & $\sqrt{ }$ & $\sqrt{ }$ & $\sqrt{ }$ & 6 \\
\hline On Friendship & $\sqrt{ }$ & $\sqrt{ }$ & $\sqrt{ }$ & $\sqrt{ }$ & $\sqrt{ }$ & $\sqrt{ }$ & 6 \\
\hline On Love & $\sqrt{ }$ & $\sqrt{ }$ & $\sqrt{ }$ & $\sqrt{ }$ & $\sqrt{ }$ & $\sqrt{ }$ & 6 \\
\hline Psalm 23 & & & $\sqrt{ }$ & & $\sqrt{ }$ & $\sqrt{ }$ & 3 \\
\hline Psalm of Life & $\sqrt{ }$ & $\sqrt{ }$ & $\sqrt{ }$ & $\sqrt{ }$ & $\sqrt{ }$ & $\sqrt{ }$ & 6 \\
\hline The Road Not Taken & & & $\sqrt{ }$ & $\sqrt{ }$ & $\sqrt{ }$ & $\sqrt{ }$ & 4 \\
\hline The Rhodora & $\sqrt{ }$ & $\sqrt{ }$ & $\sqrt{ }$ & $\sqrt{ }$ & $\sqrt{ }$ & $\sqrt{ }$ & 6 \\
\hline Song to Celia & $\sqrt{ }$ & $\sqrt{ }$ & $\sqrt{ }$ & $\sqrt{ }$ & $\sqrt{ }$ & $\sqrt{ }$ & 6 \\
\hline Sonnet 1 & $\sqrt{ }$ & & & & $\sqrt{ }$ & $\sqrt{ }$ & 3 \\
\hline Stopping by Woods & $\sqrt{ }$ & $\sqrt{ }$ & $\sqrt{ }$ & $\sqrt{ }$ & $\sqrt{ }$ & $\sqrt{ }$ & 6 \\
\hline Telephone Conversation & $\sqrt{ }$ & $\sqrt{ }$ & & $\sqrt{ }$ & $\sqrt{ }$ & $\sqrt{ }$ & 5 \\
\hline Three with the Moon & $\sqrt{ }$ & $\sqrt{ }$ & $\sqrt{ }$ & $\sqrt{ }$ & $\sqrt{ }$ & $\sqrt{ }$ & 6 \\
\hline $\begin{aligned} \text { Legend: } & \text { A-Antonymy } \\
& \text { M- Meronymy } \\
& \mathrm{N}-\text { Number of }\end{aligned}$ & & $\begin{array}{l}\text { Hy } \\
\text { Re }\end{array}$ & $\begin{array}{l}\text { tymy } \\
\text { tion }\end{array}$ & & & $\begin{array}{l}\text { ation } \\
\text { my }\end{array}$ & \\
\hline
\end{tabular}

\section{A. Lexical Patterns Evident in Selected Poems}

From the lexical mapping, patterning and content analysis done on each of the poem, it was found that the selected poems are rich in lexical patterns.
Table II shows the summary of the lexical patterns identified in each of the selected poems.

All the types of lexical patterns were identified in almost all of the selected poems. However, in the poems, Invictus by William Ernest Henley and Telephone Conversation by Wole Soyinka, only five types of lexical patterns were identified in each poem. In Robert Browning's The Road Not Taken, four types were identified; and in Psalm 23 and in Sonnet 1, only three each were noted.

The three major types of lexical patterns that were identified in the 15 poems are: repetition, synonymy and meronymy. This finding proves the precept forwarded by Transkanen [9] that the most usual lexical pattern used in written texts is Repetition.

\section{B. Cohesiveness of the Poems}

Out of the 15 poems, three were found to be very highly cohesive. These are: On Friendship of the Prophet, On Love of the Prophet and Telephone Conversation.

TABLE III: COHESIVENESS OF THE SELECTED POEMS

\begin{tabular}{lccc} 
Poems & $\mathrm{N}$ & $\bar{X}$ LexDECF & DI \\
\hline Africa & 6 & 1.93 & HC \\
How Do I Love Thee & 6 & 3.10 & $\mathrm{C}$ \\
Invictus & 5 & 2.53 & HC \\
The Little Rain & 6 & 2.79 & $\mathrm{C}$ \\
On Friendship & 6 & 1.24 & VHC \\
On Love & 6 & 0.87 & VHC \\
Psalm 23 & 3 & 2.72 & $\mathrm{C}$ \\
Psalm of Life & 6 & 1.41 & $\mathrm{C}$ \\
The Road Not Taken & 4 & 2.05 & HC \\
The Rhodora & 6 & 1.90 & HC \\
Song to Celia & 6 & 2.63 & $\mathrm{C}$ \\
Sonnet 1 & 3 & 3.93 & SC \\
Stopping by Woods & 6 & 2.16 & HC \\
Telephone Conversation & 5 & 1.41 & VHC \\
Three with the Moon & 6 & 1.98 & HC \\
\hline Leg
\end{tabular}

Legend: $\mathrm{N}$ - Number of Types of Lexical Patterns

XLexDECF - Mean of the Lexical Density of the Cohesion Field DI - Descriptive Interpretation VHC - Very Highly Cohesive

$\mathrm{HC}$ - Highly Cohesive $\mathrm{C}$ - Cohesive SC - Slightly Cohesive

Meanwhile, six poems are highly cohesive. These are: Africa, Invictus, The Road Not Taken, The Rhodora, Stopping by Woods on a Snowy Evening, and Three- With the Moon and His Shadow. Moreover, four poems are cohesive. These are: Sonnet 43: How do I love Thee, Little Rain, Psalm 23, and Song to Celia. Only one poem is found to be slightly cohesive. This is Sonnet 1 by Jose Garcia Villa. Table III shows the mean of the lexical density of the cohesion field of each of the poems and their respective descriptive interpretation.

Interestingly, On Love is identified to be the most cohesive of all the poems as it gained 0.87 mean of lexical density of the cohesion field. Only one, which is Sonnet 1, is identified as slightly cohesive because it gained 3.93 mean of lexical density of the cohesion field.

It can also be noted that the poems where all the types of lexical patterns were identified were computed as very highly cohesive (VHC) or highly cohesive (HC). This shows that the more lexical patterns a poem uses, the more cohesive it is.

\section{Themes Derived from the Poems}

The following themes are derived from the selected poems 
based on the identified lexical patterns of cohesiveness of the texts: Africa - Slavery cannot totally demean a nation; How do I Love Thee (Sonnet 43)- Love's ways cannot be gauged with concrete and definite measures; Invictus - Life may present a plethora of trying experiences, but it is up to the person how he faces and manages these experiences and consequences; The Little Rain - Nature provides for the needs of mankind; On Friendship of The Prophet - Friendship is a reciprocal relationship; On Love from The Prophet - Love directs or regulates one's course of action; Psalm 23 - The Lord leads and ensures a peaceful, secured and bountiful life for a believer; A Psalm of Life - Life is short, hence, people should make good use of it; The Road Not Taken - Making decisions is crucial because life is full of crossroads; The Rhodora, - Beauty has its own excuse for being; Song to Celia - Every person has a specific need or desire which can only be placated by the specific object of the said need or desire; Sonnet 1 - A literary piece to be called a poem must possess specific defining qualities, that is, it must be enlightening and mysterious; Stepping by the Woods on a Snowy Evening - Enticement to beauty, leisure, pleasure or rest makes one forget his/her promised tasks; Telephone Conversation - It is absurd to judge the character or credibility of a man based only on the color of his skin; and Three- With the Moon and His Shadow - Drunkenness leads to illusions.

Results show that the lexical patterns and lexical cohesiveness of a poem can direct the reader to draw the appropriate theme. Results likewise show that the identification of the lexical patterns in a poem and the high degree of cohesiveness of the poem make the drawing of the theme easier and faster. The more lexical patterns derived from a poem, the higher is the degree of its lexical cohesiveness. This further proves that the lexical patterns can effectively point to the theme.

Interestingly, the themes derived from the poems based on the identified lexical patterns and cohesiveness are regarded very acceptable by the validators. They find them to be so because they are based on careful reading and scrutiny of the denotative, connotative and sense relations of the poem's lexis. One of the validators stated that the themes are very related because they are drawn from key words which are emphasized in the poem through various modalities. The themes forwarded in this study are not based on subjective perceptions of what the poems intend to communicate. The universality of the derived themes are preserved and respected by basing them directly on the lexical items in the poem.

Another validator commented that the themes are directly related to the holistic interrelationships of the words used in the poems as explained in the analyses. The lexical patterns are exhaustively identified from the poems, hence there are enough evidences or bases on drawing the themes.

With the themes already derived, teachers and students of literature will have confidence in forwarding and explaining these in their classes because concrete pieces of lexical evidence have already been identified to prove their meanings.

Observations show that students experience difficulties in deriving themes. Experienced teachers of literature even admit that students become taciturn when asked to derive a theme from a literary piece being studied. Most likely, students become overwhelmed with too much reflections or discussions on literary features, that at the end, their awareness of the unifying message in the literary piece is strayed. To address such problem, one of the validators commented that literature teachers can use the lexical patterns as scaffolds. Scaffolding is a teaching strategy in which students are provided with guide, support or framework for them to realize the learning objectives. Hence, the themes as well as the lexical patterns are acceptable in teaching literature. Another validator said that the themes are derived using the bottom-up model, hence its relatedness to the text is guaranteed. Therefore, the themes are acceptable because they are extracted from the specific parts of the poem. The themes and the lexical patterns can be taught not only in literature classes but also in language classes such as Developmental Reading courses in college.

The validators believe that the approach used in this studyderiving the themes of the poem is similar to using the bottom-up model which is often used in reading classes. Thus, the results of this study could also be used in said classes.

All levels of students taking different courses or specializations can understand the forwarded themes in this study because they are stated in simple language. All the experts who verified the themes agree that they are clearly and explicitly stated. The themes are stated simply but intelligibly. One of the experts noted that the themes are written in cognizant to the standard definition of theme- a simple statement that embodies a universal message or observation on a vital aspect of life. Therefore, the method this study is forwarding can be used to teach the students how to craft the theme properly. It can also help them realize the difference of stating a reflection, expressing the moral and drawing the theme.

Most of the times, students tend to be superfluous in expressing the theme. In poetry analysis, themes need to be stated simply because the poem itself is already intricate. Drafting the theme of a poem is like uncurling the intricate words woven in a compact artistic piece to reveal a gem of wisdom or a light of reality.

Many students and even teachers of literature fuse reflection, moral and theme. They think that these three are the same. Hence, instead of stating the universal truth, students tend to construct or express contemplation. With these, the themes that they are deriving and bringing out to class discussions are diverse because they are subjectively drawn. Moreover, the themes sound imperative because unconsciously, students are moralizing. With the example themes presented in this study, teachers and their students are provided with models so that they can delineate reflection, moral and theme.

The validators also noted that all the themes derived in this study express precise observations about some aspects of life. One of them commented that the themes reflect the subject matters of the poems. The definite observations on these subject matters are also conveyed directly and clearly. Teachers of literature can use the themes as models in emphasizing to students that the topic or subject matter of the poem or any literary piece is different from the theme.

Distinctively, the themes and the process on how they are drawn are beneficial to students specializing in language and 
literature. These could provide a prototype for their outputs, reports or assignments. One of the validators noted that this study, the themes and the procedure used for their derivations need to be shared to students majoring in language and literature for them to learn the discipline in analyzing and critiquing literary pieces.

All of these comments prove that the derived themes in this study are acceptable, appropriate, related and verifiable.

D. Sample Lexical Mapping and Patterning of Sonnet 1 by Jose Garcia Villa

Jose Garcia Villa is recognized as a prominent Filipino poet, who became very influential in the Philippines throughout the $20^{\text {th }}$ century. Sonnet 1 is among the poems included in his anthology titled, Man Songs, which was published in 1929.

Fig. 2 shows the lexical map of the poem featuring the three dominant lexical patterns.

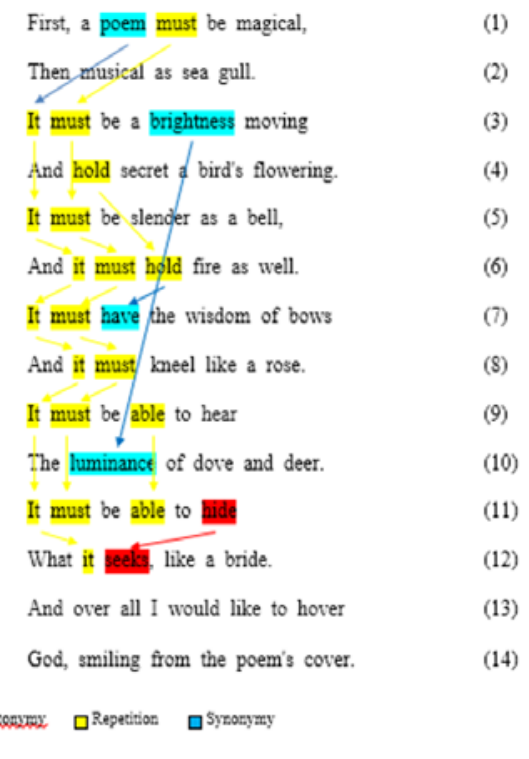

Fig. 2. Lexical Mapping of Jose Garcia Villa’s Sonnet 1.

Only three of the six types of lexical patterns were identified in the poem. Repetition has four occurrences, synonymy has three and antonymy has one. Words colored yellow show the lexical pattern, repetition. Those colored red, antonymy, and blue, synonymy.

The first key lexical item in Villa's Sonnet 1 is poem which is considered synonym of it (line 3). This pronoun is extensively repeated in the poem. Hence, it can be concluded that the whole sonnet is about poem. The third dominant lexical item is must (line 3) as it is also extensively repeated in the sonnet. Must is used in the lines as a modal verb which denotatively means necessary or important. Linking this concept to poem, it can be inferred that the speaker is citing the requirements or criteria for a poem to be considered a good poem.

The sonnet talks about the musts in poems or in writing a poem. These successive musts is supported by able which is also repeated. Able means capable or in position to do something. These repeated ables are among the musts or standards in poem. With the above mentioned cohesive devices, the speaker enumerates various standards for a poem. In fact, every line contains definite criterion. However, most emphasized are the criteria introduced by the word, hold (line
4,6 ) as it is repeated and seen as synonym of have (line 7). These two lexical items show that the poem must be having or holding certain remarkable qualities. Foremost of these qualities is brightness which is considered as synonym of luminance (line 10).

On the other hand, the antonym pair hide (line 11) and seek (line 12) suggests that the poem must be hiding at the same time seeking for something. Hence, the poem is also considered complex and mysterious.

The lexical item, poem, and its synonym, it, suggests that the subject matter is poetry. It is also inferred that it must be able to be something and must hold something. This suggests that the poet is trying to explain what a poem must possess to differentiate it from the other literary pieces. But, the lexical patterns present only two characteristics. These are 'it sheds enlightenment' and 'is mysterious'. The emphasis on only two characteristics of the poem induces uncertainty in crafting the theme because it is very obvious in the poem that the poet enumerates specific characteristics from line 1 to the end. However, there are no lexical items that are grouped together based on the sense relations that emphasizes on these other characteristics.

It is assumed therefore, that other characteristics are subsumed to the two qualities identified. Example, a part of being enlightening of the poem is its being magical (line 1), musical (line 2), slender (line 5), wise (line 7) and noble (line 14). However, some of these characteristics may also contribute to its being mysterious like magical (line 1), wise (line 7). Moreover, its characteristics of possessing a different level of sensitivity as signified in lines 8, 9, 11 and 12 are part of its mysterious character.

The theme of the poem then focuses on two specific defining qualities of a poem - enlightening and mysterious.

\section{CONCLUSIONS}

Based on the findings, it can be concluded that the poems are rich in lexical patterns and their cohesiveness provide the foundation for crafting their themes. The more lexical patterns that can be drawn from the poem, the more lexically cohesive it is, the easier to derive the theme.

Moreover, the themes derived through the aid of the lexical patterns are very acceptable. Thus, it can be forwarded that exploring the lexical patterns and cohesion of a poem is an effective tool in drawing fitting themes in poetry.

\section{RECOMMENDATIONS}

The method of identifying lexical patterns, the computation for the lexical cohesion and the manner of interpretations and analyses established in this study are proven effective through their application in different poems from the Literatures of the World. It is then recommended that the procedure be tried-out by teachers of literature not only in their GE classes but even in the major courses in literature. The Mariano Marcos State University College of Teacher Education as the leading institution in teacher education in Region I, should pioneer in encouraging their professors of literature to do such. This will be a breakthrough in teaching literature.

It is also recommended that teachers should use the results 
of this study as guide in choosing poems to be discussed in class. Deriving themes will become simpler in their classes if they will consider the cohesiveness of poems.

Students should also read the results of this study because the lexical patterns and the derived themes can help them better understand and appreciate poems. The results of this study should be shared to students because their knowledge and awareness of these results would enable them to do independent study and analysis of the poems. Furthermore, teachers and students should use lexical patterning to derive themes from other literary genres like essays and short stories.

\section{REFERENCES}

[1] V. Shklovsky, Russian Formalist Criticism: Four Essays, Linclon: Nebraska University Press, 1995.

[2] P. Verdonk, "Poems as text and discourse, the poetics of Phillip Larkin,” in Literary Pragmatics, D. Sell, Ed. London: Routledge, 1991, pp. 94-109.

[3] M. A. K. Halliday, An Introduction to Functional Grammar, London: Edward Arnold, 1985.

[4] F. Safier, Adventures in Reading, Florida: Orlando Publishing, 1985.

[5] M. H. Abrams, A Glossary of Literary Terms, New York: Harcourt Brace, 1993.

[6] S. F. Valdez and D. F. Dianco, Understanding Literary Arts and Appreciating Literatures of the World, Manila: Mindshapers, 2009.

[7] Z. Goodarzi (July 2009). Lexical patterning in poetic text: analyzing literary style. [Online]. Available: http://www.research.gate.net/ publication

[8] R. Hasan, Linguistics, Language and Verbal Art, Victoria: Deakin University, 1985

[9] S. K. Transkanen, Discourse in interaction, Canada: Routledge, 2006.

[10] M. A. K. Halliday and R. Hasan, Cohesion in English, London: Longman, 1976.

[11] E. Yeibo. (January 2011). Patterns of lexical choices and stylistic functions in J. P. Clark-Berkedermo's poetry. [Online]. Available: http://www.ccsnet.org/journal/index

[12] J. I. Saaed. (2013). An analysis of lexical meaning in Edwin Muir's the combat. [Online]. Available: http://www.Iasj.Net/oasj?Func=fulltext

[13] O. Ruxandra. (2012). Lexical peculiarities of D. H. Lawrence's poetic prose. [Online]. Available: http://www.ijcr.eu/article/105_84_pdf

[14] M. Cummings and R. Simmons, The Language of Literature, London: Penguin. 1983.

[15] M. McCarthy, Vocabulary and Language Teaching, London: Longman, 1988.

[16] K. Lotfipour-Saedi, Analysing Literary Discourse: Implications for Literary Translation, Montreal: Les Presses L’Universite Montreal, 1992.
[17] H. G. Widdowson, Stylistic and the Teaching of Literature, London: Routledge, 1995.

[18] J. A. Leech, A Linguistic Guide to English Poetry, New York: Longman Inc., 1999.

[19] D. Butt, "Ideational meaning and existential fabric of a poem," in New Developments in Systematic Linguistics, R. P. Faucett and D. S. Young, Eds. London: Printer Publishers, 1988, pp. 174-218.

[20] E. R. Babbie, The Practice of Social Research, Wadsworth: Cengage Learning, 2010.

[21] E. Hatch and H. Farhady, Research Design and Statistics for Applied Linguistics, California: Library of Congress Cataloging in Publication Data, 1981.

[22] V. Braun and V. Clarke, Successful Qualitative Research a Practical Guide for Beginners, Californi: Sage. 2006.

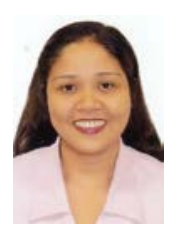

Jahnese D. Asuncion is from Laoag City, Ilocos Norte, Philippines. She is an associate professor I at the Mariano Marcos State University, College of Teacher Education (MMSU CTE), Laoag City. She has been serving the University since 2003. Aside from teaching English courses in the said College, she also serves as the student affairs coordinator and co-adviser of the official student publication, The CTE Bulletin. She had served as lecturer, resource speaker and trainer in various seminars, trainings and workshops sponsored by the MMSU CTE such as the teacher induction program and the K-12 mass training for Grade 9 teachers. She was also involved in the English crash course program for Chinese students and summer English camp for Korean students. She obtained her bachelor of secondary in education degree, major in English and minor in social studies from MMSU College of Education as magna cum laude in 2001. In 2007, she finished her master of arts in education (English) at MMSU Graduate School. She also finished her doctor of philosophy, major in linguistics in the same institution in the year 2015.

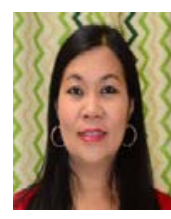

Marlina L. Lino is from the City of Batac, Ilocos Norte, Philippines. She has been passionately teaching since 1993. She finished PhD in linguistics at the Mariano Marcos State University (MMSU) in April 2010. She has served as trainer and resource speaker in several trainings, seminars and conferences in various areas of her specialization. She has likewise presented papers both here and abroad.

At present, she holds an associate professor position and is currently the coordinator of the MAEd in Ilokano Studies program of the Graduate School. Prior to this designation, she was chair of the Department of Languages and Literature of the College of Arts and Sciences, MMSU, Batac Campus from June 2011 to July 2016.

Dr. Lino is likewise currently serving as a member of the Board of Directors of the Linguistic Society of the Philippines (LSP) and as vice president of the Association of Philippine Colleges of Arts and Sciences (APCAS) Region I. 